\title{
A prospective analysis of physical examination findings in the diagnosis of facial fractures: Determining predictive value
}

\author{
Alisa Timashpolsky BA ${ }^{1}$, Alexander B Dagum MD FRCSC FACS ${ }^{1}$, Syed M Sayeed MD², \\ Jamie L Romeiser $\mathrm{MPH}^{1}$, Elisheva A Rosenfeld MD-DDS ${ }^{3}$, Nicole Conkling $\mathrm{MD}^{4}$
}

A Timashpolsky, AB Dagum, SM Sayeed, JL Romeiser, EA Rosenfeld, N Conkling. A prospective analysis of physical examination findings in the diagnosis of facial fractures: Determining predictive value. Plast Surg 2016;24(2):73-79.

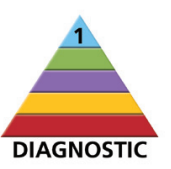

BACKGROUND: There are $>150,000$ patient visits per year to emergency rooms for facial trauma. The reliability of a computed tomography (CT) scan has made it the primary modality for diagnosing facial skeletal injury, with the physical examination playing more a cursory role. Knowing the predictive value of physical findings in facial skeletal injuries may enable more appropriate use of imaging and health care resources.

OBJECTIVE: A blinded prospective study was undertaken to assess the predictive value of physical examination findings in detecting maxillofacial fracture in trauma patients, and in determining whether a patient will require surgical intervention.

METHODS: Over a four-month period, the authors' team examined patients admitted with facial trauma to the emergency department of their hospital. The evaluating physician completed a standardized physical examination evaluation form indicating the physical findings. Corresponding CT scans and surgical records were then reviewed, and the results recorded by a plastic surgeon who was blinded to the results of the physical examination.

RESULTS: A total of 57 patients met the inclusion criteria; there were 44 male and 13 female patients. The sensitivity, specificity, positive predictive value and negative predictive value of grouped physical examination findings were determined in major areas. In further analysis, specific examination findings with $\mathrm{n} \geq 9$ (15\%) were also reported.

CONCLUSIONS: The data demonstrated a high negative predictive value of at least $90 \%$ for orbital floor, zygomatic, mandibular and nasal bone fractures compared with CT scan. Furthermore, none of the patients who did not have a physical examination finding for a particular facial fracture required surgery for that fracture. Thus, the instrument performed well at ruling out fractures in these areas when there were none. Ultimately, these results may help reduce unnecessary radiation and costly imaging in patients with facial trauma without facial fractures.

Key Words: Craniofacial; CT scan; Maxillofacial; Physical examination

\section{L'analyse prospective des résultats de l'examen physique pour diagnostiquer les fractures de la face : la détermination des valeurs prédictives}

HISTORIQUE : Plus de 150000 patients se rendent à la salle d'urgence chaque année à cause d'un traumatisme facial. En raison de sa fiabilité, la tomodensitométrie est la modalité primaire pour diagnostiquer les lésions squelettiques de la face, tandis que l'examen physique joue un rôle plus superficiel. Le fait de connaître la valeur prédictive des observations physiques en cas de lésions squelettiques de la face pourrait favoriser une utilisation plus appropriée de l'imagerie et des effectifs en matière de santé. OBJECTIF : Les chercheurs ont réalisé une étude prospective à l'aveugle afin d'évaluer la valeur prédictive de l'examen physique pour déceler une fracture maxillo-faciale chez les patients traumatisés et pour déterminer si le patient devra subir une intervention chirurgicale.

MÉTHODOLOGIE : Sur une période de quatre mois, l'équipe des auteurs a examiné les patients admis à l'urgence de leur hôpital à cause d'un traumatisme facial. Le médecin a rempli un formulaire d'évaluation de l'examen physique standardisé pour consigner ses observations physiques. Les tomodensitométries correspondantes et les dossiers chirurgicaux ont ensuite été examinés, et un plasticien a consigné les résultats sans connầtre ceux de l'examen physique.

RÉSULTATS : Au total, 57 patients respectaient les critères d'inclusion, soit 44 hommes et 13 femmes. Les chercheurs ont déterminé la sensibilité, la spécificité, la valeur prédictive positive et la valeur prédictive négative des observations groupées des examens physiques dans les principaux secteurs. À l'analyse plus approfondie, ils ont également signalé les observations tirées de de l'examen physique, où $n \geq 9$ (15\%).

CONCLUSIONS : Les données ont démontré une valeur prédictive négative élevée d'au moins $90 \%$ pour les fractures du plancher orbital, des zygomatiques, des mandibules et du nez par rapport à la tomodensitométrie. De plus, aucun des patients qui n'avait pas de fracture faciale selon l'examen physique n'a dû être opéré en raison d'une telle fracture. Ainsi, l'instrument donnait des bons résultats pour écarter ce type de fractures lorsqu'il n'y en avait pas. Au bout du compte, ces résultats peuvent contribuer à réduire des radiations inutiles et une imagerie coûteuse chez les patients ayant un traumatisme facial sans fractures.
Facial fractures are a frequent comorbidity in trauma patients, with 24\% of all trauma patients sustaining a facial injury (1). If improperly managed, such injuries can have lasting consequences including permanent asymmetry, disfigurement, malocclusion and enophthalmos (2-6). Presently, computed tomography (CT) has widely been accepted as the gold standard imaging modality in the diagnosis of facial fractures (7-11). However, a proper physical examination, devoting special attention to specific facial findings, may permit for earlier diagnosis and triage. Classically, the physical examination was the primary means by which a physician evaluated a patient with facial trauma (12) and whether a patient required surgical intervention (13). As such, certain physical examination findings have been found to correlate with the presence of a facial fracture in the zygoma $(12,14-16)$, orbit $(8,12,13,16)$, maxilla $(12,14,16,17)$, mandible $(2,12,18-20)$ and nasal bone $(12,21)$. Despite this, these findings have not been systematically tested against the CT scan to determine which findings are the most predictive of true and significant facial fractures in trauma patients.

Since 1980, CT scan use has increased 20-fold, with an estimated 62 million CT scans performed per year in the United States $(22,23)$ In many institutions, patients often undergo a facial CT scan before receiving a thorough facial physical examination by the physician $(20,24)$. The indiscriminate use of CT scans for patients with only minimal suspicion for facial trauma can result in a significant overuse

${ }^{1}$ Stony Brook University Hospital, Stony Brook; ${ }^{2}$ Nassau University Medical Center, East Meadow; ${ }^{3}$ North Shore Long Island Jewish Medical Center, Manhasset, New York; ${ }^{4}$ University of California, San Francisco, San Francisco, California, USA.

Correspondence: Dr Alexander Dagum, Stony Brook Medicine, HSCT 19, Room 60, 100 Nicolls Road, Stony Brook, New York 11791-8191, USA.

Telephone 631-444-9265, fax 631-444-6007, e-mail alexander.dagum@stonybrookmedicine.edu 


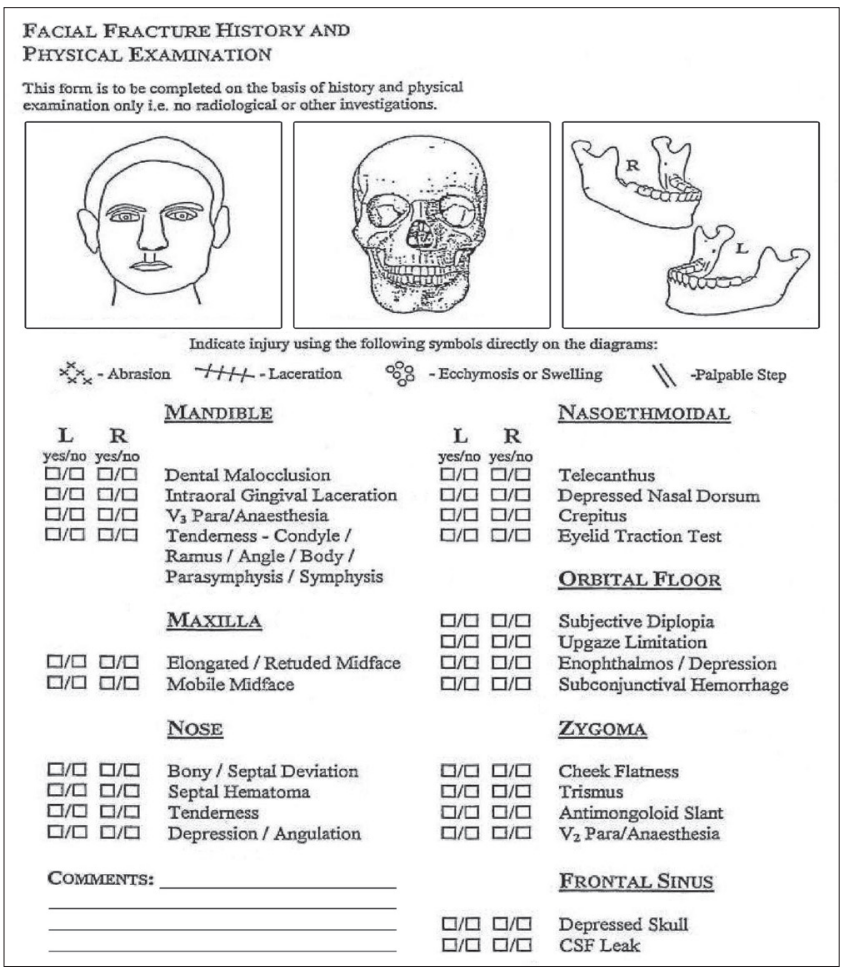

Figure 1) Facial Fracture Physical Examination Form. CSF Cerebrospinal fluid

of imaging, unwarranted radiation exposure, the potential for unnecessary consults and, ultimately, a significant added cost to the home institution. In fact, an estimated $30 \%$ of CT scans performed may be unnecessary (25). Furthermore, the excess radiation exposure has been suggested to increase the lifetime risk for developing cancer, particularly in the pediatric population $(23,25-27)$.

Due to this growing overuse of radiological imaging, several other studies have created valid diagnostic tools to decrease unnecessary imaging. One such tool, created in 1993, is the Ottawa Ankle Rules, which analyzes several clinical signs for assessing ankle injuries (28). These rules showed $100 \%$ positive predictive value for diagnosing presence of fracture, thereby reducing $\mathrm{x}$-ray radiography by one-third. By decreasing imaging, one can also decrease health care costs and exposure to unnecessary radiation. According to a multicentre study conducted in 2009 (29), each CT scan of the head delivers approximately $2 \mathrm{mSv}$ per scan, a figure 10 times higher than the amount of radiation received from one $\mathrm{x}$-ray image alone. Not only is the dose per image significantly higher for CT than conventional $\mathrm{x}$-ray radiography, patients will often undergo $>1$ CT per day when they enter the hospital. A study conducted by Mettler et al (30) reported that in patients undergoing a CT scan of the abdomen and pelvis, one-third received $\geq 3$ scans and as many as $4 \%$ receive $>9$ scans. Although we are not yet sure of the consequences of this large amount of imaging, it is important to attempt to decrease unnecessary CT scan use due to the known risk of cancer from exposure to radiation.

Previous studies have attempted to show correlations between certain physical examination findings and facial fracture. In the 1980s, when CT scans were becoming popularized, Finkle et al (11) demonstrated the accuracy of CT scan by comparing findings using three methods of diagnosing maxillofacial trauma: clinical examination; plain film x-ray with linear tomography; and computer tomography. This study showed that CT scan was the most accurate diagnostic tool for assessing facial fracture, essentially confirming CT scanning as the gold standard diagnostic tool. Another study has correlated facial lacerations and contusions in certain areas of the face and facial fracture (24), while another evaluated degree of displacement in CT scan as a means of predicting the evolution of physical examination findings postoperatively (16). Despite these previous studies, there has been no systematic comparison between physical examination findings specific to certain facial fractures and facial CT scans to determine which physical examination findings are the best at detecting and diagnosing facial fracture.

In addition to diagnostic value, the physical examination can potentially be used to determine the need for CT, and this holds the potential to decrease health care costs while maintaining optimal clinical outcomes. In 2010, Stizman et al (31) created the 'Wisconsin criteria' based on their retrospective study that found five diagnostic criteria showing significant positive predictive value (PPV) and negative predictive value (NPV) in evaluating facial fracture. These five criteria were: bony step off or instability; periorbital swelling or contusion; Glasgow Coma Scale score <14; malocclusion; and tooth absence. Collectively, these criteria had high diagnostic value in diagnosing facial fracture anywhere in the face. They did not, however, specifically test each physical examination finding and its utility in diagnosing fractures in specific areas of the facial skeleton. Additionally, the study was also retrospective, and included all positive findings from multiple examiners.

The purpose of the present study was to prospectively examine the diagnostic properties of our Facial Fracture Physical Examination Form compared with the gold standard CT scan. The present study aimed to determine the PPV and NPV of physical examination findings in the diagnosis of facial skeletal trauma. We also examined the NPV and PPV for determining the need for surgical intervention in these same patients. Finally, we retrospectively tested the Wisconsin criteria in our specific study population, and report the statistical values achieved by this diagnostic instrument for our institution's patient population. By investigating the accuracy of the physical examination for facial fractures, we hope to construct a clinical diagnostic tool in the future that can be used to assess facial trauma patients, decrease unnecessary use of diagnostic imaging and aid in diagnosis when combined with CT findings.

\section{Study design and inclusion criteria}

The present double-blinded prospective diagnostic comparison study was approved by the authors' institutional review board before commencement. Over the course of four nonconsecutive months between June 2013 and April 2014, to maintain the same examiners and researchers, patients presenting with facial trauma to the university hospital's emergency department were screened for study eligibility criteria. Patients were excluded if they had an active facial infection, facial palsy, previous facial plastic surgery, mental status changes that left them unable to respond to examiner's questions, or if they presented seven or more days following the initial trauma. Any patients not able to consent due to intubation, possible language barriers, lack of appropriate proxy or other reasons were also excluded.

\section{Physical examination form}

On consent, the evaluating physician from the plastic and reconstructive surgery (PRS) and oral and maxillofacial surgery (OMFS) services evaluated patients using the Stony Brook University (SBU, Stony Brook, New York, USA) Facial Fracture Physical Examination Form. The form was created from clinical findings described in the literature and the senior author's (ABD) clinical experience, and compiled into a comprehensive physical examination sheet shown in Figure 1. Each major fracture area, as well as subgroup area clinical finding, is described further in Table 1. For each subgroup finding, the evaluating physician indicated either 'Yes' or 'No' for both the left and right side of the face. Results for these subgroup findings were then classified as positive if either the left or the right side showed a positive finding. Physical examination major area findings were considered to be positive if any one or more of the subgroup findings showed a positive indication. It should be noted that if the CT scan occurred before the physical examination, the evaluating physician was blinded to the scan results. 
TABLE 1

Patient demographics and computed tomography (CT) scan findings of facial fractures

\begin{tabular}{|c|c|}
\hline \multicolumn{2}{|l|}{ Descriptive characteristics } \\
\hline Patients, $\mathrm{n}$ & 57 \\
\hline Age, years, mean \pm SD & $40.04 \pm 21.23$ \\
\hline \multicolumn{2}{|l|}{ Sex } \\
\hline Male & $44(77.2)$ \\
\hline Female & $13(22.8)$ \\
\hline \multicolumn{2}{|l|}{ Cause of injury } \\
\hline Assault & $21(36.8)$ \\
\hline Fall & $21(36.8$ \\
\hline Motor vehicle accident & $11(19.3)$ \\
\hline Other & $4(7.0)$ \\
\hline \multicolumn{2}{|l|}{ Non-area specific CT scan findings } \\
\hline True fracture & $52(91.0)$ \\
\hline \multicolumn{2}{|l|}{ True fractures, $n$} \\
\hline 0 & $5(8.8)$ \\
\hline 1 & $39(68.4)$ \\
\hline 2 & $7(12.3)$ \\
\hline 3 & $5(8.8)$ \\
\hline 5 & $1(1.8)$ \\
\hline \multicolumn{2}{|l|}{ Fracture type* } \\
\hline Comminution & $27(47.4)$ \\
\hline Displacement & $39(68.4)$ \\
\hline Entrapment & $1(1.8)$ \\
\hline \multicolumn{2}{|c|}{ Area-specific CT scan fractures identified } \\
\hline Mandible & $15(26.3)$ \\
\hline Maxilla & $6(10.5)$ \\
\hline Nasoethmoidal & $1(1.8)$ \\
\hline Nasal bone & $8(14.0)$ \\
\hline Orbital floor & $25(43.9)$ \\
\hline Zygoma & $18(31.6)$ \\
\hline Frontal sinus & $0(0.0)$ \\
\hline \multicolumn{2}{|c|}{ Non-area-specific physical examination findings } \\
\hline Abrasion & $3(5.3)$ \\
\hline Laceration & $16(28.1)$ \\
\hline Palpable step & $9(15.8)$ \\
\hline Ecchymosis & $37(64.9)$ \\
\hline \multicolumn{2}{|l|}{ Surgical information } \\
\hline Underwent surgery & $33(57.9)$ \\
\hline \multicolumn{2}{|l|}{ Surgery type ${ }^{\dagger}$} \\
\hline Open reduction internal fixation & $21(63.6)$ \\
\hline Maxillary mandibular fixation & $14(42.4)$ \\
\hline Reconstruction with implant & $7(21.2)$ \\
\hline Closed reduction & $6(18.2)$ \\
\hline Other & $2(6.1)$ \\
\hline
\end{tabular}

Data presented as $n(\%)$ unless otherwise indicated. *Percentages do not add to $100 \%$ because patients could have $>1$ fracture; ${ }^{\dagger}$ Percentage calculated from 33 surgical patients (note: percentages do not add to $100 \%$ because patients could have undergone $>1$ surgical procedure

Radiographic imaging

Patients underwent facial bone CT scans with three-dimensional reconstruction. The images were obtained at $1 \mathrm{~mm}$ slices in the axial plane, and were then reconstructed into the coronal and sagittal planes using these data. A single chief plastic surgery resident who was blinded to the physical examination results reviewed the original CT images. All fractures of the nasal, nasoethmoidal, zygomatic, maxillary, mandibular, orbital and frontal bone regions were classified according to diagnostic schemes proposed in the literature $(10,32)$.
TABLE 2

Physical examination findings

\begin{tabular}{|c|c|c|}
\hline Major and subarea findings & SI, n (\%) & $\begin{array}{c}\text { Examined for diagnostic } \\
\text { properties }(\mathrm{SI}>15 \%)\end{array}$ \\
\hline Mandible & $27(47.4)$ & $*$ \\
\hline Dental malocclusion & $18(31.6)$ & * \\
\hline Intraoral/gingival laceration & $11(19.3)$ & * \\
\hline V3 para/anesthesia & $8(14.0)$ & \\
\hline Tenderness total & $20(35.1)$ & * \\
\hline Ecchymosis/swelling & $5(8.8)$ & \\
\hline Palpable step & $2(3.5)$ & \\
\hline Maxilla & $3(5.3)$ & * \\
\hline Elongated/retuded midface & $2(3.5)$ & \\
\hline Mobile midface & $1(1.8)$ & \\
\hline Ecchymosis/swelling & $0(0.0)$ & \\
\hline Nose & $13(22.8)$ & * \\
\hline Bony/septal deviation & $4(7.0)$ & \\
\hline Septal hematoma & $0(0.0)$ & \\
\hline Tenderness & $12(21.1)$ & * \\
\hline Depression/angulation & $3(5.3)$ & \\
\hline Ecchymosis/swelling & $1(1.8)$ & \\
\hline Nasoethmoidal & $3(5.3)$ & * \\
\hline Telecanthus & $0(0.0)$ & \\
\hline Depressed nasal dorsum & $0(0.0)$ & \\
\hline Crepitus & $3(5.3)$ & \\
\hline Eyelid traction test & $0(0.0)$ & \\
\hline Ecchymosis/swelling & $0(0.0)$ & \\
\hline Orbital floor & $31(54.4)$ & * \\
\hline Subjective diplopia & $4(7.0)$ & \\
\hline Upgaze limitation & $5(8.8)$ & \\
\hline Enopthalmos/depression & $4(7.0)$ & \\
\hline V2 para/anesthesia & $12(21.1)$ & * \\
\hline Subconjunctival hemorrhage & $22(38.6)$ & * \\
\hline Ecchymosis/swelling & $22(38.6)$ & * \\
\hline Zygoma & $35(61.4)$ & * \\
\hline Cheek flatness & $15(26.3)$ & * \\
\hline Subconjunctival hemorrhage & $22(38.6)$ & * \\
\hline Trismus & $9(15.8)$ & * \\
\hline Antimongoloid slant & $2(3.5)$ & \\
\hline V2 para/anesthesia & $12(21.1)$ & * \\
\hline Ecchymosis/swelling & $9(15.8)$ & * \\
\hline Palpable step & $7(12.3)$ & \\
\hline Frontal sinus & $0(0.0)$ & * \\
\hline Depressed skull & $0(0.0)$ & \\
\hline Cerebrospinal fluid leak & $0(0.0)$ & \\
\hline
\end{tabular}

SI Sample incidence

Statistical analysis

Sample incidence was calculated for each of the six physical examination major fracture areas, as well as for each of the subarea-specific clinical findings. Using the CT findings as the gold standard, major common areas in the CT findings and physical examination findings (including the larger frequency subarea physical examination findings) were compared. Diagnostic properties of the physical examination, including sensitivity, specificity, PPV and NPV were calculated. Diagnostic properties of the physical examination, including sensitivity, specificity, PPV and NPV, were also assessed against surgery performed for the six major fracture areas.

Testing the Wisconsin criteria

In addition to the prospective branch of the research study, a previously published set of physical examination criteria, known as the 'Wisconsin criteria' were also used to retrospectively test these criteria 
TABLE 3

Diagnostic properties of grouped physical examination findings and individual physical examination findings that had incidence $>15 \%$

\begin{tabular}{|c|c|c|c|c|c|c|}
\hline \multirow{3}{*}{ Finding } & \multirow{2}{*}{\multicolumn{2}{|c|}{ Computed tomography (CT) findings, $n(\%)$}} & \multirow{2}{*}{\multicolumn{2}{|c|}{ Predictive value, $\%$}} & \multirow[b]{3}{*}{ Sensitivity, \% } & \multirow[b]{3}{*}{ Specificity, \% } \\
\hline & & & & & & \\
\hline & Negative & Positive & Positive & Negative & & \\
\hline (CT findings) & $42(73.68)$ & $15(26.32)$ & & & & \\
\hline Mandible & $12(28.6)$ & $15(100.0)$ & 55.6 & 100.0 & 100.00 & 71.4 \\
\hline Intraoral/gingival laceration & $4(9.52)$ & $7(46.67)$ & 63.64 & 82.61 & 47 & 90 \\
\hline Tenderness total & $5(11.90)$ & $15(100.00)$ & 75.00 & 100.00 & 100 & 88 \\
\hline (CT findings) & $49(85.96)$ & $8(14.04)$ & & & & \\
\hline Tenderness & $5(10.20)$ & $7(87.50)$ & 58.33 & 97.78 & 88 & 90 \\
\hline (CT findings) & $32(56.14)$ & $25(43.86)$ & & & & \\
\hline Orbital floor & $8(25.00)$ & $23(92.00)$ & 74.19 & 92.31 & 92 & 75 \\
\hline V2 para/anesthesia & $3(9.68)$ & $9(36.00)$ & 75.00 & 63.64 & 36 & 90 \\
\hline Subconjunctival hemorrhage & $3(9.38)$ & $19(76.00)$ & 86.36 & 82.86 & 76 & 91 \\
\hline Ecchymosis/swelling & $6(18.75)$ & $16(64.00)$ & 72.73 & 74.29 & 64 & 81 \\
\hline Trismus & $2(5.13)$ & $7(38.89)$ & 77.78 & 77.08 & 39 & 95 \\
\hline V2 para/anesthesia & $5(13.16)$ & $7(38.89)$ & 58.33 & 75.00 & 39 & 87 \\
\hline Ecchymosis/swelling & $6(15.38)$ & $3(16.67)$ & 33.33 & 68.75 & 17 & 85 \\
\hline
\end{tabular}

Areas in bold indicate grouped findings according to the specific facial region, and are considered to be positive if one finding is positive and negative if all findings are negative

on our own study population to determine how accurate this tool is at a different institution. A retrospective chart review of all patients who were included in the prospective branch of the study was performed, which searched for the following five criteria included within the initial evaluation of the patient by an OMFS resident: bony step off, periorbital swelling, Glasgow Coma Scale score $<14$, dental malocclusion and tooth absence. The percent agreement between these results and the true CT findings were subsequently calculated, and also calculated the NPV, PPV, sensitivity, and specificity for these five criteria in detecting facial fracture.

\section{RESULTS}

During the four-month study period, a total of 57 patients met the inclusion criteria; there were 44 male and 13 female patients. The mean $( \pm S D)$ patient age was $40 \pm 21$ years. Causes of injury included assault (37\%), falls (37\%), moving vehicle accident (including pedestrian involvement in moving vehicle accident [19\%]) and other (7\%). Five $(9 \%)$ patients were found to have no facial fracture on CT scan. Most patients (68\%) had one fracture, 13 (23\%) had at least two fractures. The areas with the greatest number of fractures were orbital floor (44\%), zygoma (32\%) and mandible (26\%). The fractures were also described as displaced, comminuted and/or if they showed entrapment of the soft tissues. More than one-half $(68 \%)$ of the fractures were displaced, almost one-half (47\%) comminuted and one (1.8\%) showed entrapment of the soft tissue. Slightly more than one-half $(58 \%)$ of the patients underwent surgical intervention including open reduction internal fixation (ORIF [64\%]), maxillary mandibular fixation (MMF [42\%]), open reduction and reconstruction with implant $(21 \%)$, closed reduction $(18 \%)$ or other $(6 \%)$ (Table 1$)$. Non-area specific physical examination findings, including laceration, abrasion, ecchymosis and palpable step, are also reported in Table 1.

The mandible, nasal bone, orbital floor and zygoma were considered to be 'major areas', and were evaluated in the diagnostic assessment; maxillary (pterygofacial or Lefort fractures), nasoethmoidal and frontal sinus findings were excluded due to a low incidence in this patient population. The major areas were those designated on the physical examination form and comprised the major areas of the facial skeleton, each having specific physical examination findings associated with fractures observed in those areas. Of the physical examination findings recorded, the zygomatic area had the greatest incidence (56\%), followed by the orbital floor (54\%), mandible (47\%) and nasal bone $(23 \%)$. Findings in the nasoethmoidal area and maxilla, as defined by the physical examination form, had the lowest incidence of all physical examination findings (each with only $5 \%$ ). When assessing the specific examination findings from each major facial area, subconjunctival hemorrhage and ecchymosis had the greatest incidence, each presenting in 39\% of all patients (Table 2). It should be noted that V2 para/anesthesia and subconjunctival hemorrhage are physical findings seen in fractures of both the zygoma and the orbital floor and, therefore, are included as subgroup findings under both of these major areas. Major areas and subgroup findings with at least a $15 \%$ incidence rate were further examined for diagnostic properties.

Sensitivities for the major facial fracture areas ranged from $88 \%$ to $100 \%$; specificities ranged from $51 \%$ to $88 \%$. Major-area PPV ranged from $46 \%$ to $74 \%$; NPV ranged from $91 \%$ to $100 \%$ (Table 3). Of the 24 possible physical examination findings, 11 (46\%) had adequate incidence to include for diagnostic testing.

The sensitivities for the major facial fracture areas for determining the need for surgical intervention were all $100 \%$; specificities ranged from $49 \%$ to $77 \%$. Major-area PPVs were low, ranging from $0 \%$ to $55.6 \%$; however, the NPV for each of the major area in excluding need for surgery was $100 \%$ for each major area (Table 4). This means that for those who did not have a physical examination finding in that area, $100 \%$ of them did not need surgery in that area.

Mandible

The physical examination findings for the mandible did outstanding in terms of sensitivity, correctly identifying $100 \%$ of the mandibular fractures positively identified on the CT scan. This area also showed a $100 \%$ NPV, meaning all physical examination findings classified as 'No finding' were also CT negative. However, the mandible major area had a poor PPV, with only one-half of the positive physical findings being true CT positive findings. Specificity was fair to good, correctly classifying $71 \%$ of the CT negative findings. Mandible-specific findings varied, with dental malocclusion and tenderness showing the best 
TABLE 4

Diagnostic properties of grouped physical examination findings and individual physical examination findings that had incidences $>15 \%$ compared with surgical intervention for each facial area

\begin{tabular}{|c|c|c|c|c|c|c|}
\hline \multirow[b]{2}{*}{ Finding } & \multicolumn{2}{|c|}{ Area-specific surgery, $\mathrm{n}(\%)$} & \multicolumn{2}{|c|}{ Predictive value, $\%$} & \multirow[b]{2}{*}{ Sensitivity, \% } & \multirow[b]{2}{*}{ Specificity, \% } \\
\hline & Negative & Positive & Positive & Negative & & \\
\hline (Surgery in area) & $42(73.68)$ & $15(26.32)$ & & & & \\
\hline Mandible & $12(28.57)$ & $15(100.00)$ & 55.6 & 100.00 & 100.00 & 71.4 \\
\hline Dental malocclusion & $4(9.5)$ & $14(93.3)$ & 77.78 & 97.44 & 93 & 90 \\
\hline Intraoral/gingival laceration & $4(9.52)$ & $7(46.67)$ & 63.64 & 82.61 & 47 & 90 \\
\hline Tenderness total & $5(11.90)$ & $15(100.00)$ & 75.00 & 100.00 & 100 & 88 \\
\hline (Surgery in area) & $57(100.00)$ & $0(0.00)$ & & & & \\
\hline Nose & $13(22.81)$ & $0(0.00)$ & 0.00 & 100.00 & - & 77 \\
\hline Tenderness & $12(21.05)$ & $0(0.00)$ & 0.00 & 100.00 & - & 79 \\
\hline (Surgery in area) & $48(84.21)$ & $9(15.79)$ & & & & \\
\hline Orbital floor & $22(45.83)$ & $9(100.00)$ & 29.03 & 100.00 & 100 & 54 \\
\hline V2 para/anesthesia & $6(12.77)$ & $6(66.67)$ & 50.00 & 93.18 & 67 & 87 \\
\hline Subconjunctival hemorrhage & $14(29.17)$ & $8(88.89)$ & 36.36 & 97.14 & 89 & 71 \\
\hline Ecchymosis/swelling & $15(31.25)$ & $7(77.78)$ & 31.82 & 94.29 & 78 & 69 \\
\hline (Surgery in area) & $45(78.95)$ & $12(21.05)$ & & & & \\
\hline Zygoma & $23(51.11)$ & $12(100.00)$ & 34.29 & 100.00 & 100 & 49 \\
\hline Cheek flatness & $5(5.41)$ & $10(75.00)$ & 66.67 & 95.24 & 83 & 89 \\
\hline Subconjunctival hemorrhage & $14(31.11)$ & $8(66.67)$ & 36.36 & 88.57 & 67 & 69 \\
\hline Trismus & $4(8.89)$ & $5(41.67)$ & 55.56 & 85.42 & 42 & 91 \\
\hline V2 para/anesthesia & $6(13.64)$ & $6(50.00)$ & 50.00 & 86.36 & 50 & 86 \\
\hline Ecchymosis/swelling & $6(13.33)$ & $3(25.00)$ & 33.33 & 81.25 & 25 & 87 \\
\hline
\end{tabular}

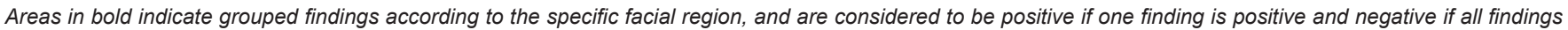
are negative

\section{TABLE 5}

Comparison of the Wisconsin criteria diagnostic properties and the Stony Brook University Hospital (SBUH, Stony Brook, New York, USA) physical examination grouped diagnostic properties for detecting facial fractures

\begin{tabular}{|c|c|c|c|c|c|c|c|}
\hline & \multicolumn{2}{|c|}{ Computed tomography fracture findings, $\mathrm{n}(\%)$} & \multicolumn{2}{|c|}{ Predictive value } & \multirow[b]{2}{*}{ Sensitivity } & \multirow[b]{2}{*}{ Specificity } & \multirow[b]{2}{*}{ Agreement } \\
\hline & Negative & Positive & Positive & Negative & & & \\
\hline Wisconsin criteria & $3(60.00)$ & $44(89.80)$ & 93.62 & 28.57 & 90 & 40 & 88.46 \\
\hline SBUH mandible & $12(28.6)$ & $15(100.0)$ & 55.6 & 100.0 & 100.0 & 71.4 & 78.95 \\
\hline SBUH nose & $6(12.24)$ & 7 (87.50) & 53.85 & 97.73 & 88 & 88 & 87.72 \\
\hline SBUH orbital floor & $8(25.00)$ & $23(92.00)$ & 74.19 & 92.31 & 92 & 75 & 82.46 \\
\hline SBUH zygoma & $19(48.72)$ & $16(88.89)$ & 45.71 & 90.91 & 89 & 51 & 63.16 \\
\hline
\end{tabular}

Data presented as \% unless otherwise indicated

diagnostic properties. Intraoral/gingival laceration, which had the lowest incidence (19\%), showed relatively poor PPV and sensitivity.

Nose

Physical examination findings for the nasal bone major area showed a high NPV (98\%), very good sensitivity and specificity (88\%), but poor PPV (54\%). Tenderness was the only specific physical examination finding with a sufficiently high incidence for examination and showed nearly identical diagnostic properties to the major area.

\section{Orbital floor}

Physical examination findings for orbital floor fractures demonstrated relatively good diagnostic properties, with a sensitivity and NPV of $92 \%$, and a specificity and PPV of approximatley $75 \%$. Each of the specific findings examined had a good specificity measure, ranging from $81 \%$ to $91 \%$.

\section{Zygoma}

Physical examination diagnostic properties for the zygoma ranged from relatively poor (PPV 46\%) to good (sensitivity 89\%), meaning that although the clinical examination was able to find most of the true positive fractures, it also had a high false-positive rate. The subgroup characteristic of cheek flatness had the highest diagnostic ability, ranging from $72 \%$ to $95 \%$ for all diagnostic tests.
Retrospective analysis of Wisconsin criteria results

Five individuals were missing data and could not be definitively categorized into having met or not met the Wisconsin criteria. Therefore, a total of 52 patients were used in this portion of the analysis. The Wisconsin criteria positively identified approximately $90 \%$ of the patients who had a fracture; however, $60 \%$ of the patients without fracture were misclassified as having a positive fracture. The sensitivity for the instrument was thus $90 \%$, but the specificity was $40 \%$ (Table 4 ).

\section{DISCUSSION}

The physical examination was once the primary means by which a physician would evaluate a trauma patient. In recent times, there has been an over-reliance on imaging to diagnose fractures in facial trauma patients. Our study attempted to scientifically test well-known physical examination findings for their ability to detect or exclude facial fracture. Overall, the mandible, orbital floor and nasal bone areas performed well in sensitivity and specificity testing.

Importantly, our data demonstrated a high NPV of at least $90 \%$ for each major area of the facial skeleton examined. Because NPV indicates what proportion of the test negatives are true negatives, our instrument appeared to perform well at excluding the presence of a fracture. For areas such as the mandible, the NPV reached 100\% for grouped findings. Thus, if a patient presented without any of the six physical examination findings evaluated for mandible, it was likely 
that the patient did not have a mandible fracture, and did not need to undergo a CT scan for that particular area's injury.

In addition to the grouped findings, our study results demonstrate certain area-specific physical examination findings to have high NPV when assessing facial fractures. These findings were dental malocclusion and tenderness for the mandible, and tenderness for the nasal bone. The findings may be used individually in assessing for fracture in these two areas of the facial skeleton and their absence indicates an unlikelihood of fracture in these areas.

In the past, other diagnostic tools, such as the Ottawa Ankle Rules, have been validated and used to decrease unnecessary imaging (28). By decreasing imaging, one can decrease health care costs and exposure to unnecessary radiation (30). In an attempt to minimize unnecessary CT scan use, several other studies have attempted to demonstrate the predictive value of certain physical examination findings. Holmgren et al (24) assessed the utility of using soft tissue facial injury as an aid in assessing whether to order a facial CT scan in patients who were already receiving a head CT. A prospective study conducted by Schwab et al (18) in 1998, assessed the sensitivity, specificity, PPV and NPV of specific physical examination findings in predicting mandibular fracture when compared with $\mathrm{x}$-ray radiography. Of the physical examination findings that were the same as those used in the present study, dental malocclusion performed the best, with an NPV of $87 \%$. This correlates well with our own data, as dental malocclusion had the best NPV of all the individual characteristics we examined for the mandible (97.44\%).

Another prospective study performed by Exadaktylos et al (3)in 2005, examined physical examination findings pertinent to orbital floor fractures, such as diplopia, blepharohematoma, and enophthalmos/exophthalmos in 600 consecutive patients admitted to a level 1 trauma centre. Their results showed that isolated ecchymosis of the orbit (blepharohematoma) had a PPV of 58.3\%, rendering this finding a poor diagnostic tool for ruling in orbital fracture. They did not, however, demonstrate the NPV for these findings and, therefore, their data could not be used to exclude the existence of fracture and subsequently decrease unnecessary imaging.

In a retrospective study, Sitzman et al (31) examined 34 distinct clinical findings associated with facial trauma in their maxillofacial study population. Clinical findings were considered to be positive if mentioned by any one of a team of practitioners examining the patient. Of these clinical findings, five distinct diagnostic criteria emerged as predictors for ordering facial CT imaging. The five criteria instrument, called the 'Wisconsin' criteria, was designed to identify non-area specific fractures in any part of the facial skeleton. The Wisconsin score was developed from single-centre retrospective data, which was later used to validate the criteria on the same patient population, potentially leading to an overinflated prediction value. Furthermore, in their retrospective review a finding was considered positive if it was mentioned by any one of a multitude of practitioners examining the patient. Although two of the five Wisconsin criteria overlap with two area subfindings presented in the current study dental malocclusion and periorbital edema - the Wisconsin instrument was designed as a global instrument to detect or exclude facial fractures. In contradistinction, our study attempted to prospectively analyze physical examination findings that are distinct to different areas of the facial skeleton and their utility in diagnosing fractures of specific facial bones.

Understanding these differences in both study type and instrument purpose, we attempted to examine how the Wisconsin criteria would perform at our institution. When these criteria were applied to our study population, the NPV and specificity were $<50 \%$. This poor performance may be due to the fact that within our study population, there was a very high incidence of facial fracture in general. Because the Wisconsin criteria were created to assess all trauma patients admitted to the ED, our study population may not have afforded itself well to analysis with these criteria. Our study population consisted of all patients who required a facial trauma consult, which may have skewed the data and only included patients that have a higher level of suspicion for facial fractures, rendering the patients a preselected population. Therefore, the Wisconsin criteria were worse at excluding fracture presence than our own criteria, but did well in detecting facial fractures. Ultimately, our two instruments differ a great deal from one another because the Wisconsin criteria are better for screening large populations of polytrauma patients, while our own clinical criteria are better at excluding fracture presence in patients who have a higher suspicion for facial fracture in specific areas of the facial skeleton.

A limitation in using the physical examination to assess facial trauma patients in the immediate postimpact time period is that the clinical examination may evolve over time due to changes that occur in the soft tissue. Immediately following trauma, a patient may experience increased swelling of the facial area that has undergone fracture, thereby limiting the examiner's ability to appreciate certain findings $(6,11)$. This limitation was reflected in our data, with cheek flatness having a high specificity (95\%) but lower sensitivity (72\%). Additionally, palpable step only had an incidence of $12 \%$ of the zygomatic fractures; however, all patients who were found to have palpable step had evidence of fracture on the CT scan.

Three of the major fracture areas that we sought to assess were not represented in the data, including pterygomaxillary, nasoethmoidal and frontal sinus fractures. Our low incidence of fractures in these areas is not unexpected because fractures in these areas are associated with high-energy trauma and the majority of these patients will require intubation or have a decrease level of consciousness from a head injury, excluding them from our study population. Nevertheless, with a significantly larger study population, these facial area findings could be adequately tested (4).

Our results show that the physical examination is useful in excluding facial fracture in trauma patients. Furthermore, and more relevant, it shows that in the absence of any physical examination findings, a patient will most likely not require surgical intervention. Future work is needed to increase the power of the present study, and examination of the psychometric properties of our instrument is crucial. Increasing the sample size through a multicentre study may provide a wider array of facial fractures to be assessed, including the three areas that were poorly represented in the present study. A multicenre study would overcome limitations such as geographic and demographic biases, which inherently impact cause, workup, and follow-up on diagnoses; recruiting efforts for a multi-institutional study are currently underway. This would also enable testing of the inter-rater reliability of the physical examination form. Demonstrating consistency among different examiners is a critical step in understanding the contribution this assessment tool may have in facial trauma patients. Such results may ultimately change the course of care by reducing unnecessary imaging and, thereby, reduce costs and excess radiation.

DISCLOSURES: The authors have no financial disclosures or conflicts of interest to declare.

\section{REFERENCES}

1. National Trauma Data Bank Annual Report [Database Online]. $<$ www.facs.org/ /media/files/quality\%20programs/trauma/ntdb/ ntdb\%20annual\%20report\%202013.ashx> United

States: American College of Surgeons; 2013. (Accessed July 26, 2014).

2. Myall RW, Sandor GK, Gregory CE. Are you overlooking fractures of the mandibular condyle? Pediatrics 1987;79:639-1.

3. Exadaktylos AK, Sclabas GM, Smolka K, et al. The value of computed tomographic scanning in the diagnosis and management of orbital fractures associated with head trauma: A prospective, consecutive study at a level I trauma center. J Trauma 2005;58:336-41.

4. Press BH, Boies LR Jr, Shons AR. Facial fractures in trauma victims: The influence of treatment delay on ultimate outcome. Ann Plast Surg 1983;11:121-4. 
5. Modabber A, Rana M, Ghassemi A, et al. Three-dimensional evaluation of postoperative swelling in treatment of zygomatic bone fractures using two different cooling therapy methods: A randomized, observer-blind, prospective study. Trials 2013;14:238.

6. Linneau KF, Stanley RB, Hallama DK, Gross JA, Mann FA. Imaging of high-energy midfacial trauma: What the surgeon needs to know. Eur J Radiol 2003;48:17-32.

7. Jenkins $\mathrm{CN}$, Thuau $\mathrm{H}$. Ultrasound imaging in assessment of fractures of the orbital floor. Clin Radiol 1997;52:708-11.

8. Salvolini U. Traumatic injuries: Imaging of facial injuries. Eur Radiol 2002;12:1253-61.

9. Neumann PR, Zilkha A. Use of the CAT scan for diagnosis in the complicated facial fracture patient. Plast Reconstr Surg 1982;70:683-93

10. Manson PN, Markowitz B, Mirvis S, Dunham M, Yaremchuk M. Toward CT-based facial fracture treatment. Plast Reconstr Surg 1990;85:202-12.

11. Finkle DR, Ringler SL, Luttenton CR, Beernink JH, Peterson NT, Dean RE. Comparison of the diagnostic methods used in maxillofacial trauma. Plast Reconstr Surg 1985;75:32-41.

12. Jurkiewicz MJ, Nickell WB. Fractures of the skeleton of the face. A study of diagnosis and treatment based on twelve years' experience in the treatment of over 600 major fractures of the facial skeleton. J Trauma 1971;11:947-58.

13. Schouman T, Courvoisier DS, Van Issum C, Terzic A, Scolozzi P. Can systematic computed tomographic scan assessment predict treatment decision in pure orbital floor blowout fractures? J Oral Maxillofacial Surg 2012;70:1627-32.

14. Zachariades N, Papavassiliou D, Papademetriou I. The alterations in sensitivity of the infraorbital nerve following fractures of the zygomaticomaxillary complex. J Craniomaxillofac Surg 1990;18:315-8.

15. Strong EB, Sykes JM. Zygoma complex fractures. Facial Plast Surg $1998 ; 14: 105-15$

16. Mueller CK, Zeiss F, Mtsariashvili M, Thorwarth M, SchultzeMosgau S. Correlation between clinical findings and CT-measured displacement in patients with fractures of the zygomaticomaxillary complex. J Craniomaxillofac Surg 2012;40:e93-98.

17. Romano JJ, Manson PN, Mirvis SE, Dunham M, Crawley W. Le Fort fractures without mobility. Plast Reconstr Surg 1990;85:355-62.

18. Schwab RA, Genners K, Robinson WA. Clinical predictors of mandibular fractures. Am J Emerg Med 1998;16:304-5.

19. Marchena JM, Padwa BL, Kaban LB. Sensory abnormalities associated with mandibular fractures: Incidence and natural history. J Oral Maxillofac Surg 1998;56:822-5.
20. Thai KN, Hummel RP, 3rd, Kitzmiller WJ, Luchette FA. The role of computed tomographic scanning in the management of facial trauma. J Trauma 1997;43:214-7.

21. Gharehdaghi J, Samadi Rad B, Ghatreh Samani V, Kolahi F, Khatami Zonoozian A, Marashian SM. Comparison of physical examination and conventional radiography in diagnosis of nasal fracture. Ind J Otolaryngol Head Neck Surg 2013;65(Suppl 2):304-7.

22. Bhargavan M. Trends in the utilization of medical procedures that use ionizing radiation. Health Phys 2008;95:612-27.

23. Brenner DJ, Hall EJ. Computed tomography - an increasing source of radiation exposure. N Engl J Med 2007;357:2277-84.

24. Holmgren EP, Dierks EJ, Assael LA, Bell RB, Potter BE. Facial soft tissue injuries as an aid to ordering a combination head and facial computed tomography in trauma patients. Journal of Oral and Maxillofacial Surgery. May 2005;63:651-4.

25. Sun Z, Ng KH, Vijayananthan A. Is utilisation of computed tomography justified in clinical practice? Part I: Application in the emergency department. Singapore Med J 2010;51:200-6.

26. Huang WY, Muo CH, Lin CY, et al. Paediatric head CT scan and subsequent risk of malignancy and benign brain tumour: A nationwide population-based cohort study. Br J Cancer 2014;110:2354-60.

27. Brenner DJ, Elliston CD. Estimated radiation risks potentially associated with full-body CT screening. Radiology 2004;232:735-8.

28. Stiell IG, Greenberg GH, McKnight RD, et al. Decision rules for the use of radiography in acute ankle injuries. Refinement and prospective validation. JAMA 1993;269:1127-32.

29. Smith-Bindman R, Lipson J, Marcus R, et al. Radiation dose associated with common computed tomography examinations and the associated lifetime attributable risk of cancer. Arch Intern Med 2009;169:2078-86.

30. Mettler FA Jr, Wiest PW, Locken JA, Kelsey CA. CT scanning: Patterns of use and dose. J Radiol Prot 2000;20:353-9.

31. Sitzman TJ, Hanson SE, Alsheik NH, Gentry LR, Doyle JF, Gutowski KA. Clinical criteria for obtaining maxillofacial computed tomographic scans in trauma patients. Plast Reconstr Surg 2011;127:1270-8.

32. Follmar KE, Baccarani A, Das RR, Erdmann D, Marcus JR, Mukundan S. A clinically applicable reporting system for the diagnosis of facial fractures. Int J Oral Maxillofac Surg 2007;36:593-600. 